\title{
Adherence and Persistence with Methotrexate in Rheumatoid Arthritis: A Systematic Review
}

\author{
Jeffrey R. Curtis, Vivian P. Bykerk, Maher Aassi, and Michael Schiff
}

\begin{abstract}
Objective. Medication adherence in patients with rheumatoid arthritis (RA) is typically suboptimal. Nonadherence has been associated with symptom worsening and increased disability. We systematically reviewed published clinical studies to evaluate methotrexate (MTX) adherence and persistence, factors associated with MTX adherence and persistence, and the effect of MTX nonadherence on clinical outcomes in RA.

Methods. MEDLINE and Embase were systematically searched (inception to February 2016) using relevant keywords. Observational or interventional clinical studies in patients with RA that specifically reported adherence to or persistence with MTX were included. Data were extracted using a predesigned, standardized template that included study design, patient demographics, and relevant outcomes. Main outcomes were MTX adherence and persistence rates in patients with RA treated with MTX and factors associated with MTX adherence and persistence.

Results. Of 365 references screened, 31 articles met inclusion criteria and another 10 were identified from searching reference lists. Estimates of MTX adherence varied from study to study because of heterogeneity in patient populations, duration of followup, definitions of adherence, and methods of assessment. Rates of MTX persistence ranged from $50 \%$ to $94 \%$ at 1 year and $25 \%$ to $79 \%$ at 5 years. No clear trends were identified in factors that influence MTX adherence and persistence. Two studies suggested that MTX adherence was associated with superior clinical outcomes.

Conclusion. MTX adherence and persistence are highly variable in patients with RA. Research is necessary to determine the effect of nonadherence on health outcomes and to identify independent predictors of nonadherence to inform evidence-based interventions. (First Release October 1 2016; J Rheumatol 2016;43:1997-2009; doi:10.3899/jrheum.151212)
\end{abstract}

Key Indexing Terms:

METHOTREXATE

RHEUMATOID ARTHRITIS
OUTCOME ASSESSMENT

\section{PATIENT COMPLIANCE RISK FACTORS}

Highly effective pharmacotherapeutic options are available for treating patients with rheumatoid arthritis (RA). Nonetheless, many patients fail to achieve remission ${ }^{1,2}$, increasing the

From the Division of Clinical Immunology and Rheumatology, University of Alabama at Birmingham, Birmingham, Alabama; Inflammatory Arthritis Center, Hospital for Special Surgery, New York, New York; Rheumatology Division, University of Colorado School of Medicine, Greenwood Village, Colorado, USA; Department of Rheumatology, Mount Sinai Hospital, Toronto, Ontario, Canada; F. Hoffmann-La Roche Ltd., Basel, Switzerland.

Funding for manuscript preparation was provided by F. Hoffmann-La Roche Ltd. J.R.C. has received fees from F. Hoffmann-La Roche, UCB, Janssen, Corrona, and Amgen. M.A. is an employee of F. Hoffmann-La Roche Ltd. M.S. has received fees from AbbVie, Bristol-Myers Squibb, and F. Hoffmann-La Roche.

J.R. Curtis, MD, MS, MPH, Division of Clinical Immunology and Rheumatology, University of Alabama at Birmingham; V.P. Bykerk, MD, Inflammatory Arthritis Center, Hospital for Special Surgery, and Department of Rheumatology, Mount Sinai Hospital; M. Aassi, MD, F. Hoffmann-La Roche Ltd.; M. Schiff, MD, Rheumatology Division, University of Colorado School of Medicine.

Address correspondence to Dr. J.R. Curtis, Division of Clinical Immunology and Rheumatology, University of Alabama at Birmingham, 510 20th St. South, FOT 802D, Birmingham, Alabama 35294, USA.

E-mail: jcurtis@uab.edu

Full Release Article. For details see Reprints/Permissions at jrheum.org. Accepted for publication July 9, 2016. likelihood of functional deterioration ${ }^{1,3}$ and additional clinic visits, laboratory tests, and treatment modifications.

Although reasons for not achieving or for losing disease control are complex, one factor that may influence outcome is medication adherence, defined as the degree to which a patient takes medication in accordance with clinician instructions ${ }^{4}$. Persistence is considered an aspect of adherence and may be defined as the time from therapy initiation to discontinuation $^{5,6}$. According to the World Health Organization, risk factors/predictors for nonadherence may be categorized based on 5 interacting dimensions: socioeconomic, healthcare system-related, disease-related, therapy-related, and patient-related ${ }^{4}$.

In RA, medication adherence is highly variable and typically suboptimal, with reports of adherence to conventional disease-modifying antirheumatic drugs (DMARD) ranging from $22 \%$ (underuse) to $107 \%$ (overuse) ${ }^{5,7,8}$. Nonadherence to DMARD has been associated with symptom worsening and increased disability ${ }^{9,10}$, and high adherence has been linked to lower disease activity ${ }^{11,12}$. A previous narrative review found no clear pattern in factors that influence medication adherence in patients with $\mathrm{RA}^{5}$, whereas a systematic review of methotrexate (MTX) use in

Personal non-commercial use only. The Journal of Rheumatology Copyright (c) 2016. All rights reserved. 
RA suggested improved adherence was associated with belief in the necessity and efficacy of MTX, absence of low mood, mildness of disease, and monotherapy with $\mathrm{MTX}^{13}$.

MTX is recommended as a first-line treatment in patients with active RA ${ }^{14,15}$, and because of its additive efficacy benefits and its reductions in immunogenicity, is typically used in combination with biologics ${ }^{16}$. Although several systematic or comprehensive reviews have evaluated adherence to DMARD in general ${ }^{7,17,18}$, only 1 systematic study, to our knowledge, has specifically evaluated MTX adherence (but not persistence) in patients with RA ${ }^{13}$. Given the prevalence of MTX use and its involvement in combination treatment with biologics, it is important to understand factors that may cause patients to be nonadherent or to discontinue treatment.

Our aims were to systematically review published clinical studies to evaluate MTX adherence and persistence in patients with RA treated with MTX alone or in combination with nonbiologic or biologic DMARD, to identify factors that influence adherence and persistence, and to determine the effect of nonadherence on clinical outcomes.

\section{MATERIALS AND METHODS}

Literature search. A systematic literature search was conducted according to the Preferred Reporting Items for Systematic reviews and Meta-Analyses statement. The MEDLINE (through PubMed) and Embase databases were searched using combined Medical Subject Headings (MeSH) and free text terms related to "methotrexate," "rheumatoid arthritis," "adherence," "compliance," and "persistence" (see Supplementary Table 1 for the full search strategy, available online at jrheum.org). Studies were limited to those published in English. No publication date or study type limits were applied. The original search was performed on November 1, 2013, and was updated on February 5, 2016. Additional articles were obtained by manually searching reference lists of relevant articles.

Study selection. Eligible publications reported results of an observational or interventional study that included adults with RA treated with MTX as monotherapy or in combination with other DMARD or biologics. Studies were included only if they reported adherence to or persistence with MTX in patients with RA as an outcome. No further exclusion criteria were applied.

All authors independently screened the titles and abstracts of all studies identified in the literature search for relevance. The relevance of each article was then discussed, and the full text of each potentially relevant article was obtained and screened.

Data extraction and quality assessment. For each study, the following were extracted using a predesigned, standardized template: study design, funding sources, patient recruitment method, setting, data collection dates, inclusion/exclusion criteria, sample size, demographics and characteristics [age, sex, RA definition, RA duration, disease activity, comorbidities, and concomitant therapies, including folate supplementation (folic or folinic acid)], followup duration, MTX dosage and administration route, MTX line of therapy, method of measuring adherence/persistence, MTX adherence/persistence rate, factors that influenced adherence/persistence (if available), effect of nonadherence/non-persistence on clinical outcomes (if available), and statistical analyses undertaken. If studies included both univariate and multivariate analyses of influencing factors or clinical outcomes, only multivariate results were extracted.

Given that no single tool is recommended for assessing quality or susceptibility to bias in observational studies, we used a simple methodology checklist that assessed the risk for bias within each study. This included the representativeness of the study sample, whether an RA diagnosis had been clinically confirmed, how loss to followup was accounted for, appropriateness of the outcome measure, risk for missing/erroneous information, and appropriate accounting for confounders (where applicable). Data extraction and quality assessment were performed by 1 person and verified by another.

The primary outcomes were MTX adherence and persistence rates in adults with RA treated with MTX. Secondary outcomes were factors associated with MTX adherence and persistence and the effect of nonadherence/non-persistence on clinical outcomes.

\section{RESULTS}

The search of MEDLINE and Embase identified 365 citations after duplicates were removed; another 10 studies were identified from manual searching of reference lists. Forty-one studies met all criteria and were included (Figure 1). For each study, data were extracted and quality was assessed. Results are summarized in Table $1^{9,11,12,19,20,21,22,23,24,25,26,27}$, Table 2, Table $3^{28-37,38-47,48,49,50,51,52,53,54,55,56}$, and Table 4, as well as Supplementary Table 2 and Supplementary Table 3 (available online at jrheum.org).

MTX adherence. Twelve studies were identified that evaluated MTX adherence in patients with RA (Table 1) $)^{9,11,12,19,20,21,22,23,24,25,26,27 ~ . ~ M o s t ~ p a t i e n t s ~ w e r e ~ e n r o l l e d ~ i n ~}$ rheumatology outpatient clinics and were receiving MTX for the first time (Supplementary Table 2, available online at jrheum.org).

Assessment of study quality found that most studies had notable susceptibility to bias (Table 2). Five studies included populations unlikely to be representative of the general population (enrollment in a social healthcare program for persons with low income and limited resources ${ }^{21}$, RA duration $<1 \mathrm{yr}^{9}$, predominantly men ${ }^{11}$, sample from an outpatient clinic in India ${ }^{24}$, and economically disadvantaged ${ }^{12}$ ). Accounting for loss of followup was insufficient in many studies.

Adherence was evaluated using a Medication Event Monitoring System (MEMS; electronic chip that records medicine bottle opening) in 4 studies ${ }^{12,19,25,26}$. In the largest study of 129 patients receiving MTX, 58\% were completely adherent and $91 \%$ were at least $80 \%$ adherent over the 16 -week study period ${ }^{26}$. In another study of 23 patients taking MTX for the first time, the mean percentage of prescribed doses taken was $107 \%$ over 6 months (overuse) ${ }^{19}$. When adherence was assessed as the mean percentage of doses taken at the correct time (a more stringent measure), the rate decreased to $83 \%$ over 6 months. A third study used MEMS to evaluate MTX adherence in an ethnically diverse, economically disadvantaged US population $(n=76)^{12}$. Compared with patients who did not agree to monitoring, those monitored were more likely to be younger, female, and Hispanic. No differences were seen in disease characteristics or self-reported adherence. The mean percentage of correctly taken MTX doses over 2 years was 63\%. In the final MEMS study, the proportion that was at least $80 \%$ adherent to MTX (alone or with another DMARD) decreased from $91.2 \%$ at 3 months to $69.3 \%$ at 12 months ${ }^{25}$.

Personal non-commercial use only. The Journal of Rheumatology Copyright $\odot$ (2016. All rights reserved 
Table 1. Adherence to MTX and associated factors in patients with RA.

\begin{tabular}{|c|c|c|c|c|c|}
\hline \multirow[t]{2}{*}{ Study } & \multirow{2}{*}{$\begin{array}{l}\text { Patients } \\
\text { Receiving } \\
\text { MTX, n }\end{array}$} & \multirow[b]{2}{*}{$\begin{array}{l}\text { Duration of } \\
\text { Followup }\end{array}$} & \multirow[b]{2}{*}{ Measurement } & \multicolumn{2}{|c|}{ Adherence to MTX } \\
\hline & & & & $\begin{array}{l}\text { Adherence Definition: } \\
\text { Rate }\end{array}$ & $\begin{array}{c}\text { Factors Associated } \\
\text { with Adherence }\end{array}$ \\
\hline de Klerk, et $_{a l}{ }^{19}$ & 23 & $6 \mathrm{mos}$ & MEMS & $\begin{array}{l}\text { Mean percentage of prescribed doses } \\
\text { taken: } 107 \%\end{array}$ & $\begin{array}{l}\text { (+) Less frequent dosing }{ }^{\mathrm{a}} \\
(+) \text { Female sex }{ }^{\mathrm{a}}\end{array}$ \\
\hline & & & & Mean doses taken at correct dosage: $81 \%$ & (+) Better coping ${ }^{\mathrm{a}}$ \\
\hline $\begin{array}{l}\text { Contreras-Yáñez, } \\
\text { et al }\end{array}$ & 93 & $6 \mathrm{mos}$ & Drug record registry ${ }^{c}$ & $\begin{array}{l}\text { MTX taken correctly } \geq 80 \% \text { of time: } \\
78 \% \text { (monotherapy), } 14 \%-49 \% \\
\text { (combination therapy) }\end{array}$ & $\begin{array}{c}(-) \text { Higher ESR } \\
\text { (-) Combination therapy vs } \\
\text { monotherapy }\end{array}$ \\
\hline Marwaha, et al ${ }^{24}$ & 50 & $3 \mathrm{mos}$ & $\begin{array}{l}\text { Patient self-report, } \\
\text { interview }\end{array}$ & $\begin{array}{l}\text { Patients who took all } \\
\text { MTX doses as prescribed: } 92 \%\end{array}$ & $\mathrm{NR}$ \\
\hline Waimann, et al ${ }^{12}$ & 76 & $2 \mathrm{yrs}$ & MEMS & $\begin{array}{l}\text { Weeks in which patients took } \\
\text { MTX as prescribed: } 63 \%\end{array}$ & $\begin{array}{l}\text { (+) Being married or having } \\
\text { significant other } \\
\text { (+) Lower disease activity } \\
\text { (+) Better mental health }\end{array}$ \\
\hline De Cuyper, et $a l^{26}$ & 129 & $4 \operatorname{mos}$ & $\begin{array}{l}\text { MEMS, CQR } \\
\text { score, MARS-5 } \\
\text { score, VAS }\end{array}$ & $\begin{array}{c}\geq 80 \% \text { adherent at } 4 \text { mos (MEMS): } \\
91 \%, \geq 80 \% \text { adherent at } 16 \text { weeks }(\mathrm{CQR}) \text { : } \\
85.7 \%, \text { mean MARS } 5 \text { score at } 16 \text { weeks: } \\
24.2 \text {, mean adherence at } 16 \text { weeks (VAS): } 94 \%\end{array}$ & $\begin{array}{l}\text { (+) Comorbidities } \\
(+) \text { Better mental health } \\
(-) \text { Living alone }\end{array}$ \\
\hline \multicolumn{6}{|c|}{ Retrospective studies by publication yr } \\
\hline Harley, et $a l^{20}$ & 1668 & $1 \mathrm{yr}$ & Claims data & $\mathrm{MPR}^{\mathrm{d}} \geq 80 \%: 64 \%$ & NR \\
\hline Grijalva, et $a l^{21}$ & $\mathrm{NR}^{\mathrm{e}}$ & 180 days & Claims data & Median MPR ${ }^{\mathrm{d}} 59 \%, 95 \%$ CI 31-82 & $\mathrm{NR}$ \\
\hline de Thurah, et $a l^{22, a}$ & 941 & $\begin{array}{c}\text { Median 12.5 } \\
\text { mos, IQR 7.3-30.6 }\end{array}$ & Claims data & Mean $\mathrm{CMG}^{\mathrm{f}} 12.3 \%$ g, $95 \%$ CI $11.5-13.2$ & $\begin{array}{c}(+) \mathrm{CRP}>32 \mathrm{ng} / \mathrm{l} \\
(-) \text { Ulcer/mild liver disease } \\
(-) \text { Age }>67 \mathrm{yrs}\end{array}$ \\
\hline Cannon, et $a l^{11}$ & 455 & $\begin{array}{c}\text { Mean } 42.7 \pm 31.2 \\
\operatorname{mos}\end{array}$ & Claims data & $\mathrm{MPR}^{\mathrm{d}} \geq 80 \%$ over first course of MTX: $84 \%$ & $\begin{array}{l}\text { (+) White } \\
\text { at enrollment } \\
(+) \text { Lower ESR at enrollment }\end{array}$ \\
\hline
\end{tabular}

\footnotetext{
${ }^{a}$ Indicates adherence to DMARD in general, not specifically to MTX (specific analysis for MTX not reported). ${ }^{b}$ Eighty-five patients at baseline and 65 patients at 9-month followup. ${ }^{\mathrm{c}}$ Standardized form that records name, dose, timing, and frequency of MTX use in the 7 days before the interview was completed by the participant. ${ }^{\mathrm{d}}$ No. prescribed days of MTX during a course divided by the total duration of days of the course. ${ }^{\mathrm{e}}$ Overall, 14,586 patients with RA contributed 28,906 new episodes of medication use; the specific no. patients who received MTX was not reported. ${ }^{\mathrm{f}}$ Calculated as the days of treatment gaps divided by total days between first prescription and last prescription. This can be interpreted as the percentage of days not covered by medication. ${ }^{\mathrm{g}}$ Implies that 10.5 months were covered by MTX if patients were followed up for 1 year. MTX: methotrexate; RA: rheumatoid arthritis; IQR: interquartile range; MEMS: Medication Event Monitoring System; CQR: Compliance Questionnaire Rheumatology; MARS-5: Medication Adherence Report Scale; VAS: visual analog scale; MPR: medication possession ratio; CMG: continuous measure of medication gap; ESR: erythrocyte sedimentation rate; NR: not reported; CRP: C-reactive protein; DMARD: disease-modifying antirheumatic drugs.
}

Claims data were used to assess adherence in 5 studies $11,20,21,22,27$. In each, patients were followed from first MTX use (or prescription gap $\geq 180$ days). Harley, et $a l^{20}$ calculated the medication possession ratio (MPR; number of prescribed days of MTX during a course divided by total course duration) for MTX in commercial and Medicare enrollees in a large US health plan $(\mathrm{n}=1668)$. Throughout 1 year, $64 \%$ were adherent to MTX (MPR $\geq 80 \%$ ). In a Medicaid-managed care program, median MPR over 180 days was $59 \%^{21}$. In an analysis of a German sickness fund,
MPR was $60 \%$ at 2 years if the entire period was considered, irrespective of whether patients were actively prescribed MTX; however, if only periods when patients were prescribed MTX were considered, MPR increased to $95 \% 27$. One study ${ }^{22}$ used prescription data to perform a 10 -year longitudinal study among Danish patients who were first-time MTX users. Adherence was assessed using a continuous measure of medication gaps (number of days when medication was unavailable divided by total course duration) to give a mean of $12.3 \%$, corresponding to

Personal non-commercial use only. The Journal of Rheumatology Copyright @ 2016 . All rights reserved. 


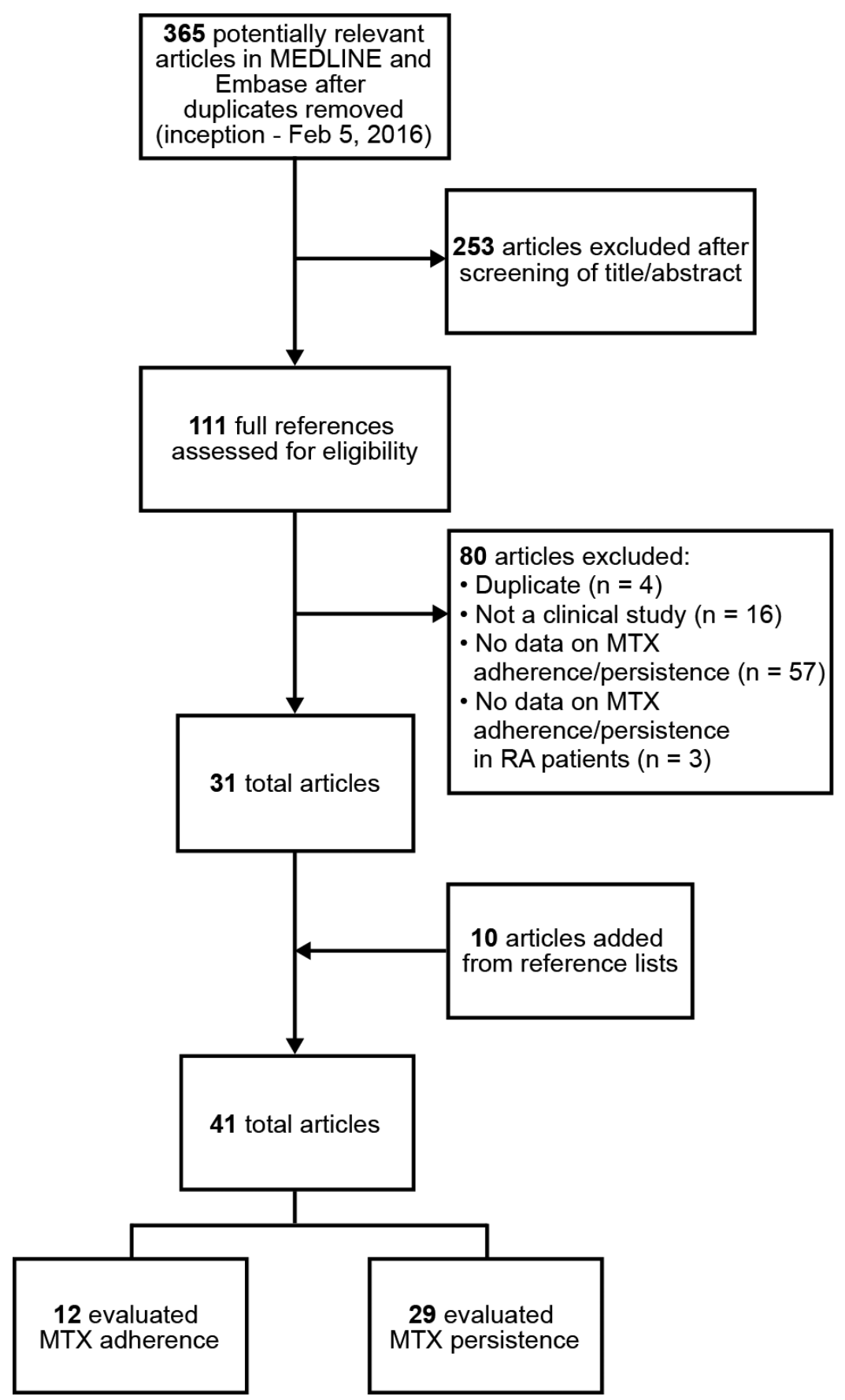

Figure 1. Flow chart of study selection process. MTX: methotrexate; RA: rheumatoid arthritis.

10.5 months/year of MTX coverage if patients were followed for 1 year. Finally, in a retrospective analysis of a US Veterans Affairs Rheumatoid Arthritis registry ${ }^{11}, 84 \%$ were considered adherent over the first course of MTX (MPR $\geq 80 \%$ ). One of the study's main limitations was that $92 \%$ of the population was men, making it non-representative of the general RA population.

The remaining studies used various methods of patient reporting to evaluate adherence ${ }^{9,23,24}$. In a 9 -month prospective Danish study that evaluated beliefs about medication, patients who were first-time MTX users were identified through a prescription database and completed the Compliance Questionnaire Rheumatology (CQR) at baseline and 9 months $^{23}$. The median CQR score was 70.1 [interquartile range (IQR) 36.8-93.0] at baseline and 70.6 (IQR 42.1-91.2) at 9 months. However, $23 \%$ did not complete the 9-month evaluation, baseline CQR scores were higher in completers, and completers believed more strongly in the 
Table 2. Bias assessment of studies that evaluated adherence to methotrexate in patients with RA.

\begin{tabular}{|c|c|c|c|c|c|c|}
\hline Study & $\begin{array}{l}\text { Representativeness } \\
\text { of the Sample }\end{array}$ & \multirow[t]{2}{*}{ 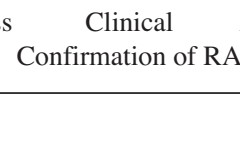 } & \multirow[t]{2}{*}{$\begin{array}{l}\text { Appropriate Accounting for } \\
\text { Loss to Followup }\end{array}$} & \multirow[t]{2}{*}{$\begin{array}{l}\text { Completeness and } \\
\text { Accuracy of Data }\end{array}$} & \multirow[t]{2}{*}{$\begin{array}{l}\text { Appropriateness of } \\
\text { Adherence Measure }\end{array}$} & \multirow[t]{2}{*}{$\begin{array}{l}\text { Appropriate Accounting } \\
\text { for Confounders }\end{array}$} \\
\hline Prospective studies & & & & & & \\
\hline de Thurah, et $a l^{23}$ & + & + & $?$ & $+/-$ & $+/-$ & + \\
\hline Contreras-Yáñez, et $a l^{9}$ & - & $?$ & + & $+/-$ & - & $+/-$ \\
\hline Marwaha, et $a l^{24}$ & - & ? & - & - & - & NA \\
\hline De Cuyper, et $a l^{26}$ & $+/-$ & + & $+/-$ & + & + & + \\
\hline \multicolumn{7}{|l|}{ Retrospective studies } \\
\hline Harley, et $a l^{20}$ & + & - & $?$ & $+/-$ & $+/-$ & NA \\
\hline Grijalva, et $a l^{21}$ & - & - & - & $+/-$ & $+/-$ & NA \\
\hline de Thurah, ${\text { et } a l^{22}}^{2}$ & + & - & $?$ & $+/-$ & $+/-$ & + \\
\hline Cannon, et $a l^{11}$ & - & + & $?$ & $+/-$ & $+1-$ & - \\
\hline
\end{tabular}

RA: rheumatoid arthritis; +/-: adequate; ?: unclear; NA: not applicable.

necessity of MTX and were less concerned about side effects and potential longterm consequences than those who dropped out. In a 6-month prospective study in patients with early arthritis in Mexico, patients with RA durations < 1 year completed a standardized drug record registry that recorded doses, timing, and frequency of DMARD use in the 7 days before the interview ${ }^{9}$. Adherence, defined as percentage of doses taken correctly $\geq 80 \%$ of the time, was $78 \%$ for patients treated with monotherapy and 14-49\% for patients treated with MTX in combination with other DMARD. A patient report was also used to evaluate MTX adherence in patients with RA at a rheumatology outpatient clinic in India ${ }^{24}$. Of the patients who returned for the 3-month visit $(n=50), 92 \%$ stated that they had taken MTX as prescribed. One study ${ }^{26}$ used 3 self-report questionnaires - CQR, Medication Adherence Rate Score, and a visual analog scale (VAS) in addition to the MEMS to assess MTX adherence. VAS correlated best with the MEMS results $(r=0.552, p<0.001)$, giving a mean adherence rate of $94 \%$ over the 16 -week study $^{26}$.

Persistence with MTX. Twenty-nine studies evaluated persistence with MTX (Table 3) 28-37,38-47,48,49,50,51,52,53,54,55,56. Most were in the United States and Europe, and 1 each in Israel, India, and Japan. Mean/median doses of MTX ranged from $3.8 \mathrm{mg} /$ week to $20 \mathrm{mg} /$ week (Supplementary Table 3, available online at jrheum.org).

Different definitions of MTX discontinuation were used across studies, including MTX withdrawal, adding another treatment to MTX, or MTX interruption. Some studies included patients treated with first-line MTX, and others included patients who had previously received DMARD or MTX by a different route. This made it difficult to directly compare persistence duration. Persistence rates ranged from $50 \%$ to $94 \%$ at 1 year and $25 \%$ to $79 \%$ at 5 years. Lack of tolerability was the main reason for withdrawal $(23 \%-79 \%$ of withdrawals). The highest withdrawal rates owing to tolerability occurred in a Japanese study ${ }^{45}$. Inefficacy was the other primary reason for withdrawal (6\%-72\% of withdrawals).

Assessment of bias susceptibility found that earlier studies tended to include patients from 1 center only, and in general, reports did not include details about how data were verified for accuracy or completeness (Table 4). Further, few accounted for different thresholds for MTX discontinuation between physicians or documented key potential modifiers of persistence such as folate supplementation.

Factors that influence MTX adherence and persistence. Clinical, demographic, and biologic factors that may influence MTX adherence were assessed in several studies (Table 1 and Table 5), with no clear patterns observed. A multiple regression analysis adjusted for age, sex, comorbidities, duration of RA, C-reactive protein (CRP), hemoglobin, concomitant therapies, and year of inclusion found ulcer/mild liver disease independently predicted worse adherence (adjusted estimate 0.04, 95\% CI 0.004-0.084), whereas CRP > $32 \mathrm{ng} / \mathrm{l}$ predicted better adherence than CRP $<8 \mathrm{ng} / \mathrm{l}$ (adjusted estimate -0.04 , 95\% CI -0.070 to $-0.015)^{22}$. In another study ${ }^{9}$, higher erythrocyte sedimentation rate (ESR) remained independently associated with nonadherence (OR 1.03, 95\% CI 1.01-1.05, p = 0.003), as did > 3 concomitant DMARD versus no concomitant DMARD (OR 31 .5, 95\% CI 2.3-433.3, p = 0.009) in a multiregression analysis that included age, years of education, followup at clinic, Health Assessment Questionnaire (HAQ) score, sex, socioeconomic status, rheumatoid factor, comorbidities, and corticosteroid use.

A direct (non-adjusted) comparison of clinical variables between patients whose MPR were $<80 \%$ and those whose MPR were $\geq 80 \%$ found significantly more white patients $(\mathrm{p}=0.05)$ and fewer African American patients $(\mathrm{p}=0.01)$ in the adherent group ${ }^{11}$. At enrollment, adherent patients had

Personal non-commercial use only. The Journal of Rheumatology Copyright $\subset$ 2016. All rights reserved. 


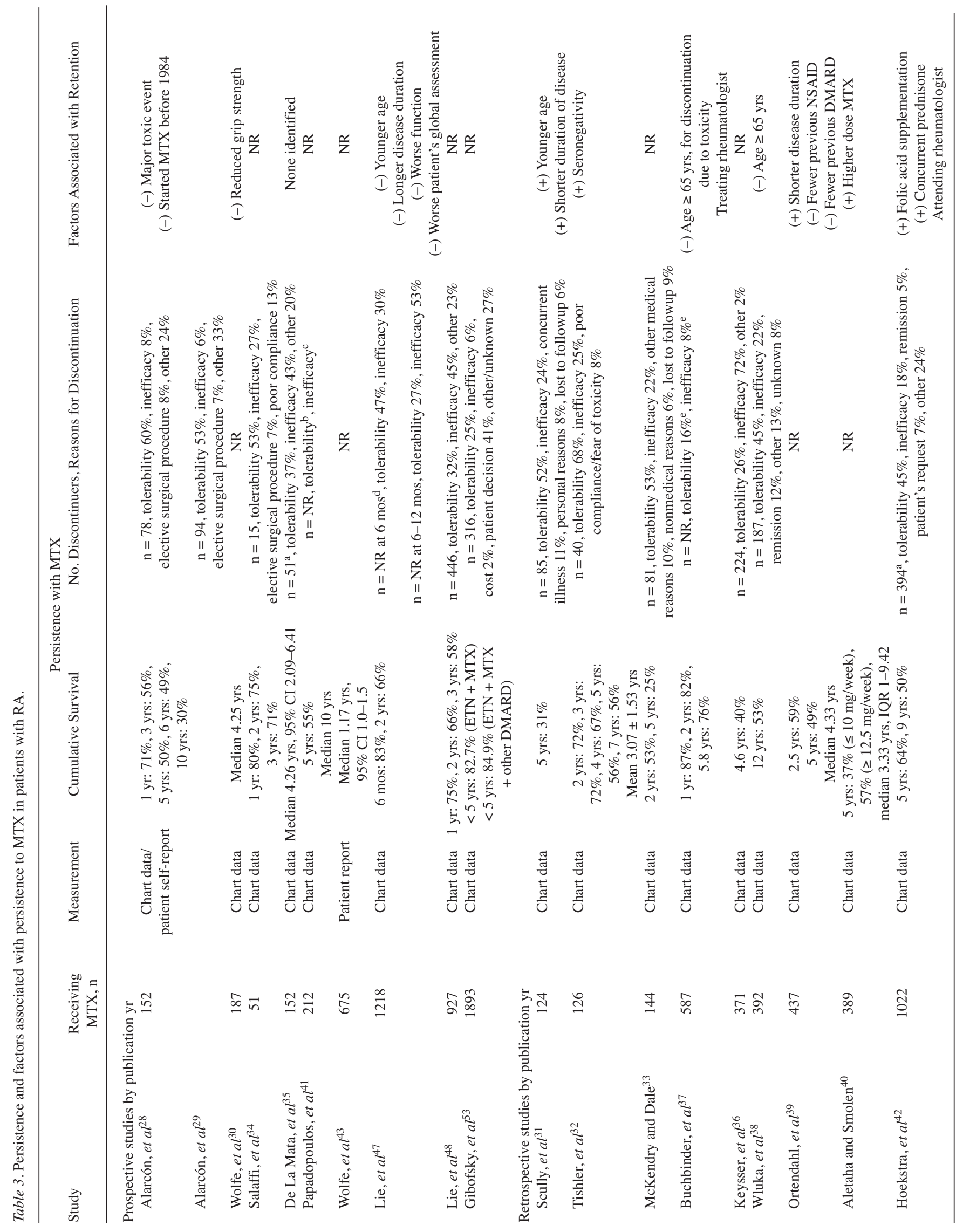

Personal non-commercial use only. The Journal of Rheumatology Copyright @ 2016 . All rights reserved. 


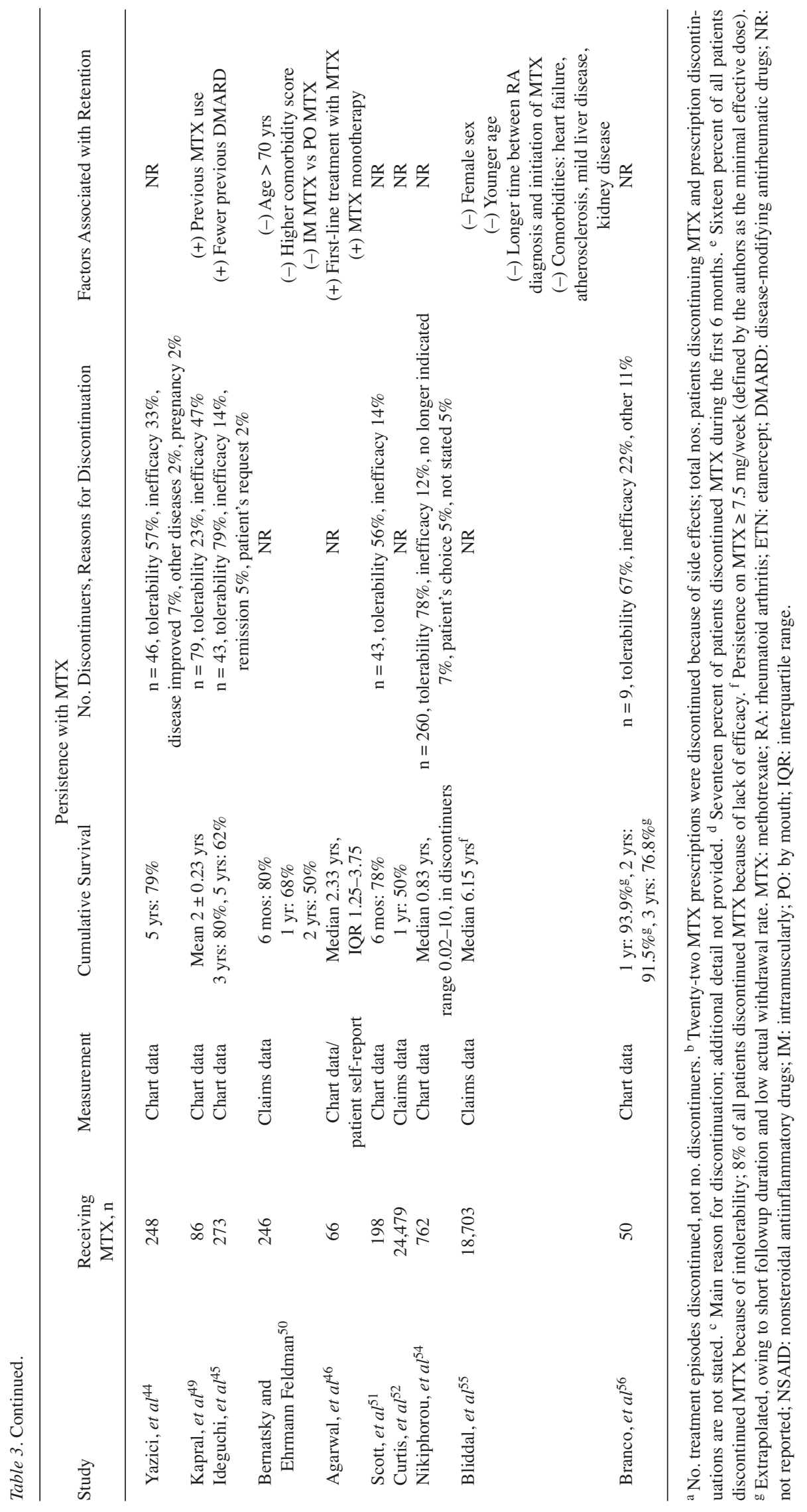

Personal non-commercial use only. The Journal of Rheumatology Copyright (C) 2016. All rights reserved. 
Table 4. Bias assessment of studies that evaluated persistence with methotrexate in patients with RA.

\begin{tabular}{|c|c|c|c|c|c|}
\hline $\begin{array}{l}\text { Repre } \\
\text { of }\end{array}$ & $\begin{array}{l}\text { esentativeness } \\
\text { the Sample }\end{array}$ & $\begin{array}{c}\text { Clinical Confirmation } \\
\text { of RA }\end{array}$ & $\begin{array}{l}\text { Appropriate Accounting } \\
\text { for Loss to Followup }\end{array}$ & $\begin{array}{l}\text { Completeness and } \\
\text { Accuracy of Data }\end{array}$ & $\begin{array}{l}\text { Appropriate Accounting } \\
\text { for Confounders }\end{array}$ \\
\hline \multicolumn{6}{|l|}{ Prospective studies } \\
\hline Wolfe, et $a l^{30}$ & - & $?$ & + & $+1-$ & $+/-$ \\
\hline Salaffi, et $a l^{34}$ & $+/-$ & + & + & $+/-$ & NA \\
\hline De La Mata, et $a l^{35}$ & $+/-$ & + & $+/-$ & $+/-$ & NA \\
\hline Lie, et $a l^{47}$ & + & - & + & $+1-$ & NA \\
\hline $\mathrm{Lie}$, et $a l^{48}$ & + & + & + & $+1-$ & NA \\
\hline Gibofsky, et $a l^{53}$ & $?$ & + & - & - & - \\
\hline \multicolumn{6}{|l|}{ Retrospective studies } \\
\hline Scully, et $a l^{31}$ & $+/-$ & + & + & $+1-$ & NA \\
\hline Tishler, et $\mathrm{l}^{32}$ & $+1-$ & + & + & $+1-$ & $?$ \\
\hline Ortendahl, et $a l^{39}$ & $+/-$ & + & + & $+1-$ & $+/-$ \\
\hline Aletaha and Smolen ${ }^{40}$ & $+1-$ & + & + & $+1-$ & - \\
\hline Hoekstra, et $a l^{42}$ & + & $?$ & + & $+1-$ & + \\
\hline Yazici, et al ${ }^{44}$ & - & + & + & $+1-$ & NA \\
\hline Kapral, et al ${ }^{49}$ & - & + & - & $+1-$ & NA \\
\hline Ideguchi, et $a l^{45}$ & $+/-$ & + & - & $+1-$ & + \\
\hline Bernatsky and Ehrmann Feldman 50 & + & - & - & $+/-$ & + \\
\hline Agarwal, et $a l^{46}$ & $?$ & + & - & - & $?$ \\
\hline Scott, et al ${ }^{51}$ & $?$ & $?$ & - & - & NA \\
\hline Curtis, et al ${ }^{52}$ & + & $?$ & ? & $?$ & NA \\
\hline Nikiphorou, et al $l^{54}$ & $?$ & $?$ & $?$ & $?$ & NA \\
\hline Bliddal, et $a l^{55}$ & + & - & $?$ & $+1-$ & $+1-$ \\
\hline
\end{tabular}

RA: rheumatoid arthritis; +/-: adequate; ?: unclear; NA: not applicable.

better clinical measures [mean Disease Activity Score at 28 joints (DAS28), $p=0.02$; tender joint count (TJC), $p=0.02$; swollen joint count (SJC), $p<0.01]$ and lower ESR $(p=0.02)$ than nonadherent patients. There were no differences in age, disease duration, smoking status, autoantibody status, or concurrent therapy use in the adherent versus the nonadherent group. One study ${ }^{23}$ compared clinical and demographic variables in patients who had CQR scores in the bottom quartile with those who had CQR scores in the upper 3 quartiles. After 9 months of treatment, no significant differences in MTX dose or HAQ score were reported between groups. Another study ${ }^{26}$ used multivariate analysis to show that better mental health status, presence of comorbidities, and not living alone predicted $30 \%$ of variance in MTX adherence.

Several studies evaluated factors that influence adherence to rheumatology medications in general rather than with specific regard to MTX. A multivariate regression analysis found that disease-controlling drugs (compared with symptommodifying drugs), less frequent dosing, female sex, better coping, and perception of poorer health together explained $66.6 \%$ of adherence variation ${ }^{19}$. A stepwise regression analysis using the percentage of correct DMARD doses taken as the dependent variable showed adherence was associated with being married/having a significant other/not being widowed or separated $(\mathrm{p}<0.01)$, having lower disease activity $(\mathrm{p}<0.05)$, and having better mental health $(\mathrm{p}<0.05)^{12}$.

Factors that influenced MTX persistence were reported in several studies (Table 3 and Table 5). In a Cox regression analysis that included disease severity, age, and race, Alarcón et $a l^{28,29}$ found a higher risk for MTX discontinuation in patients who experienced a toxic event $(\mathrm{p}=0.028)$ or began MTX treatment at an earlier year $(\mathrm{p}=0.001)$. One study ${ }^{37}$ reported older age ( $\geq 65 \mathrm{yrs}$ ) increased the likelihood of discontinuation because of toxicity $(\mathrm{p}<0.001)$ and noted that treatment termination rates varied between rheumatologists, particularly because of differences in withdrawal attributed to toxicity. Cox regression analysis on baseline covariates and length of the MTX therapeutic segment found that these factors were associated with shorter MTX persistence: longer disease duration $(p=0.002)$, fewer previous nonsteroidal antiinflammatory drugs $(p=0.003)$, and fewer previous DMARD $(p=0.034)$. These factors did not have significant effect: age at disease onset, pain score, disability index,

Personal non-commercial use only. The Journal of Rheumatology Copyright @ 2016. All rights reserved. 
Table 5. Summary of factors associated and not associated with MTX adherence and persistence.

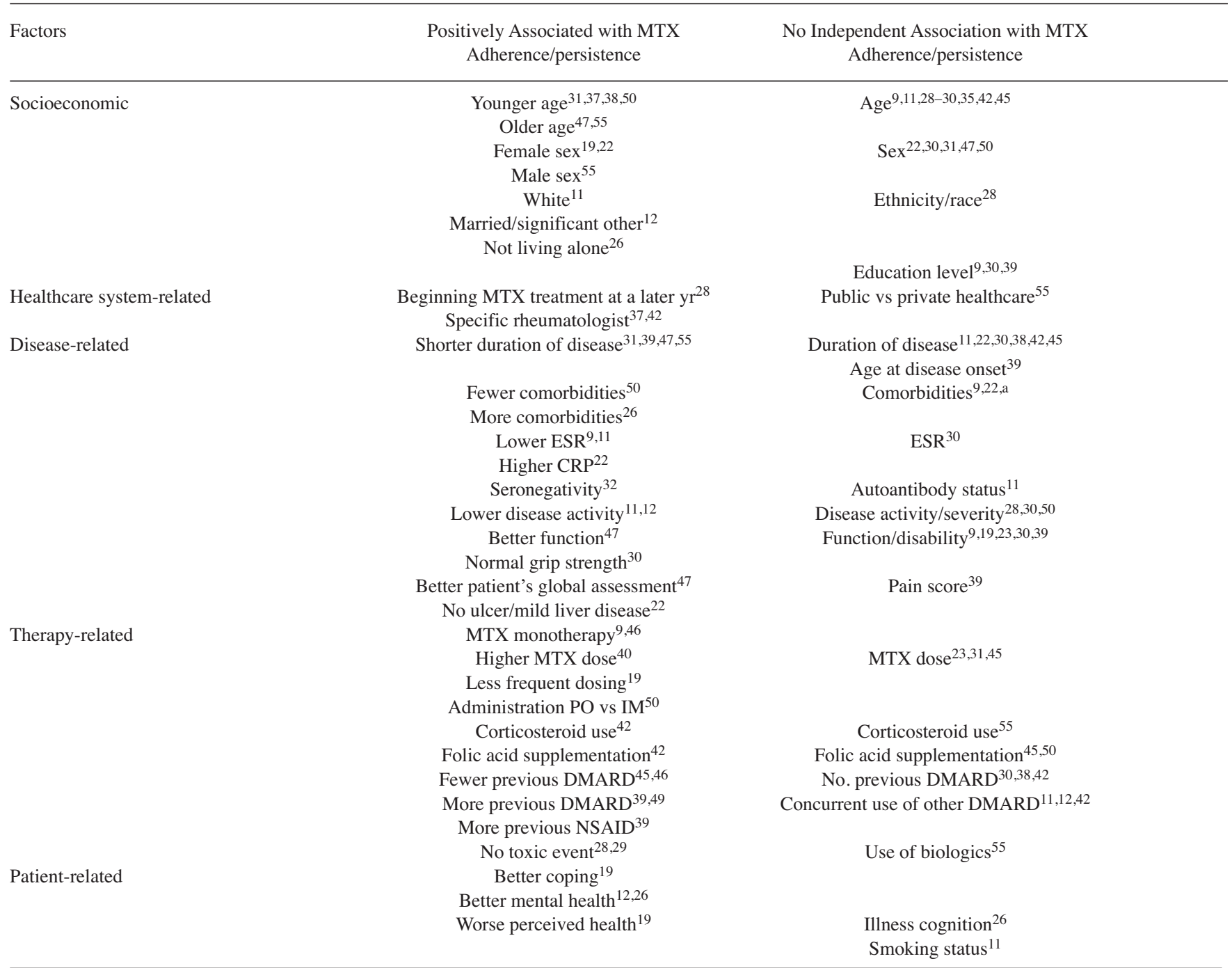

\footnotetext{
${ }^{a}$ Comorbidities with no independent association with MTX adherence/persistence in de Thurah, et $a l^{22}$ include heart disease, chronic pulmonary disease, diabetes, and cancer. MTX: methotrexate; ESR: erythrocyte sedimentation rate; CRP: C-reactive protein; PO: by mouth; IM: intramuscularly; DMARD: disease-modifying antirheumatic drugs; NSAID: nonsteroidal antiinflammatory drugs.
}

global assessment, and education level ${ }^{39}$. In patients treated with MTX between 1993 and 2001 ${ }^{42}$, multivariate analysis found folate supplementation [relative risk (RR) related to MTX discontinuation 0.25, 95\% CI 0.20-0.33, p < 0.001], prednisolone use (RR 0.70, 95\% CI 0.54-0.90, $\mathrm{p}=0.005$ ), and attending rheumatologist $(\mathrm{p}=0.002)$ were related to MTX retention. No independent association was found with current sulfasalazine use, number of previous DMARD, or age. Analysis of a large Canadian database of patients $\geq 65$ years with newly diagnosed RA showed age $>70$ years [adjusted hazard ratio (HR) 1.4, 95\% CI 1.0-2.0], comorbidity score (adjusted HR 1.1, 95\% CI 1.0-1.2), and intramuscular versus oral MTX (adjusted HR 2.4, 95\% CI 1.1-5.7) were all independently associated with MTX discon- tinuation ${ }^{50}$. No significant association was found among sex, folic acid use, and RA disease severity.

MTX dose may also have an effect on persistence. In 1 study, differences in persistence between patients treated with higher doses $(\geq 12.5 \mathrm{mg} /$ week) and lower doses $(\leq 10$ $\mathrm{mg} /$ week) of MTX significantly favored higher dose treatment for median retention time $(\mathrm{p}<0.05)$ and 5-year persistence rate $(\mathrm{p}<0.05)$. However, factors such as disease severity, RA duration, and MTX administration era might have confounded these results ${ }^{40}$. In a study in Japan ${ }^{45}$, where MTX doses are generally lower than in Western countries, multiregression analysis showed that no previous DMARD use (relative to previous DMARD use $\geq 3$ ) was an independent predictor of MTX survival (adjusted RR 2.07, 95\% CI

Personal non-commercial use only. The Journal of Rheumatology Copyright $\subset$ 2016. All rights reserved. 
1.09-3.95, $\mathrm{p}=0.027$ ), whereas MTX dose, folate supplementation, disease duration, and age were not significant.

Effect of MTX nonadherence or non-persistence on clinical outcomes. Only 2 articles specifically evaluated the effect of MTX nonadherence on clinical outcomes ${ }^{11,25}$. A retrospective study in patients at US Veterans Affairs medical centers found patients with MTX MPR $\geq 80 \%$ had better DAS28 scores $(\mathrm{p}=0.02), \operatorname{ESR}(\mathrm{p}=0.05), \operatorname{CRP}(\mathrm{p}=0.03), \mathrm{TJC}(\mathrm{p}<0.01)$, and SJC $(\mathrm{p}=0.02)$ than those with MTX MPR $<80 \%$ (unadjusted analysis) ${ }^{11}$. No association was found between adherence and HAQ score, patient's global score, or pain. A multivariate analysis adjusted for RA classification criteria, medical history, smoking status, education, ethnicity, age, sex, RA duration, previous/current DMARD use, seropositivity, and comorbidities showed a significant independent association between the DAS2 8 score and MTX MPR $\geq 80 \%$ $(-0.37,95 \%$ CI -0.67 to $-0.07, \mathrm{p}<0.05)$. No adjustment for baseline DAS28 was possible because some patients were already established in receiving MTX at study initiation. When the analysis was limited to the incident MTX subpopulation and baseline DAS28 score was included in the covariates, the association between MTX adherence and DAS28 lost statistical significance $(-0.40,95 \% \mathrm{CI}-1.11$ to 0.30 ). Nonadherence to MTX (alone or with DMARD) has been independently associated with poorer DAS28 score for up to 6 months after treatment initiation; however, this effect was lost after 6 months ${ }^{25}$.

\section{DISCUSSION}

Patients with RA are often required to take a cocktail of medications by different routes and at varying times, which may lead to issues with medication adherence. MTX remains the initial drug of choice for most patients and is typically used in combination with biologics. Therefore, adequate adherence to MTX remains a major therapeutic goal.

In our systematic review, estimates of MTX adherence were shown to vary considerably because of differences in patient populations, followup durations, adherence definitions, and assessment methods. Wide variation in persistence rates was also seen and may be attributed to factors such as time of study, lines of therapy, MTX dosage, and differences in rheumatologists' thresholds for MTX termination. In most studies, more patients discontinued because of tolerability than inefficacy. Interestingly, a claims database analysis of patients with RA initiating MTX found that although about one-half discontinued MTX at 1 year, more than one-third subsequently restarted $\mathrm{MTX}^{52}$. One study found patients who received MTX subcutaneously were less likely to add or switch to another nonbiologic DMARD or to add a biologic DMARD than patients treated with oral MTX ${ }^{57}$.

MTX adherence or persistence may be superior to that seen with other conventional DMARD ${ }^{19,21,35,36,40,41,48}$, but not with biologics ${ }^{20,48}$. Direct comparisons are difficult to make, however, because of inherent biases in nonrandomized studies possibly related to weekly dosing, side effects, or differences in clinical characteristics in patients prescribed MTX compared with other DMARD. In addition, the side effects of MTX can be at least partially mitigated by use of concomitant folate, which is not the case for other DMARD.

Most of the identified factors that influence MTX adherence are inherent to the disease, treatment, or patient and are difficult to manipulate to improve adherence or persistence. Some reasons associated with poor adherence may be modifiable (e.g., MTX dose, higher folate doses, or switch to folinic acid/leucovorin). Although most studies investigating MTX dose as a factor that influenced adherence did not find an independent association ${ }^{23,31,45}, 1$ study found that a higher dose was associated with better persistence ${ }^{40}$. Reasons for withdrawal were not reported, however, making this finding difficult to interpret. Folic/folinic acid use has been shown to reduce overall withdrawals from $\mathrm{MTX}^{58}$, but a general lack of reporting of folate supplementation in the studies in the review makes commenting on the potential effect of this variable on persistence problematic. In the few studies that included folate supplementation as a covariate in regression analysis, 1 found a positive association between supplementation and adherence ${ }^{42}$; other reports, including 1 in which patients received low-dose MTX (mean dosage $5.5 \mathrm{mg} /$ week), found no relationship ${ }^{45,50}$.

The effects of concomitant biologics on MTX adherence or persistence are also difficult to gauge. Two studies indicated no association between biologic use and MTX adherence ${ }^{12,55}$, whereas among patients initiating MTX therapy in a Veterans Affairs registry, a higher proportion of nonadherent patients than adherent patients were treated with concomitant tumor necrosis factor antagonists $(\mathrm{p}=0.04)^{11}$. However, patient numbers were relatively small.

Few studies have examined interventions to improve adherence in patients with RA. One study ${ }^{59}$ did not find that targeting beliefs about medication had any effect on DMARD adherence. Another study ${ }^{60}$ found that supplying a nonadherent patient's rheumatologist with a report about medication use and adherence did not change adherence or the patient's beliefs about medicine.

Several studies ${ }^{9,12,61,62}$ have shown that patients with better adherence generally have less disease activity. Only 2 studies ${ }^{11,25}$ specifically evaluated the effect of MTX adherence on clinical outcomes. One study ${ }^{11}$ suggested that high rates of adherence were associated with improved DAS28 and that disease activity measures were superior at baseline in adherent users already established in receiving MTX, but not in incident users, likely reflecting that patients with better adherence already had better clinical outcomes. Nevertheless, the non-representative design of the population (veterans, 92\% men) and the lack of ability to adjust for baseline DAS28 scores make definitive conclusions difficult. In another study ${ }^{25}$, the effects of MTX adherence on DAS28 were lost over time, possibly because a step-up in therapy

Personal non-commercial use only. The Journal of Rheumatology Copyright $@$ (2016. All rights reserved. 
might have occurred in patients with poor outcomes. Of course, as in any cohort study, it is difficult to disentangle causal relationships; it may be that poor disease control is the driving factor of poor adherence rather than the reverse. Similarly, adherent patients often have better outcomes, irrespective of the underlying therapy, because their attention to other health-promoting strategies is often superior to that of nonadherent patients.

Our systematic review has a number of limitations, largely because of the heterogeneity of available data. Some studies had populations that made it difficult to generalize results to the typical RA population, and others were performed several decades ago and may include outdated practices, such as using low doses of MTX, which might have influenced persistence rates because of inefficacy, or no folate supplementation, which might have contributed to increased toxicity-related withdrawals. Changes in MTX prescribing have occurred over time. Current practice is to prescribe doses of about $15 \mathrm{mg} /$ week; many patients are able to tolerate doses of $\geq 20 \mathrm{mg} / \mathrm{week}$, and folate supplementation is routine. In addition, all studies included in our review were nonrandomized. Many were susceptible to bias, mainly because of lack of clarity around how patients who were lost to followup were accounted for, data accuracy, and representativeness of the sample population.

MTX adherence and persistence are suboptimal in patients with RA. Measuring adherence is not standardized, but should be part of routine clinical practice. No consistent variables have been identified regarding MTX adherence or persistence. Research is necessary to determine the effect of MTX nonadherence on health outcomes in patients with RA and to identify independent predictors of nonadherence to inform the development of evidence-based interventions.

\section{ACKNOWLEDGMENT}

We thank Juliette Allport and ApotheCom, who provided writing services on behalf of F. Hoffmann-La Roche Ltd.

\section{ONLINE SUPPLEMENT}

Supplementary data for this article are available online at jrheum.org.

\section{REFERENCES}

1. Navarro-Millán I, Chen L, Greenberg JD, Pappas DA, Curtis JR. Predictors and persistence of new-onset clinical remission in rheumatoid arthritis patients. Semin Arthritis Rheum 2013;43:137-43.

2. Shahouri SH, Michaud K, Mikuls TR, Caplan L, Shaver TS, Anderson JD, et al. Remission of rheumatoid arthritis in clinical practice: application of the American College of Rheumatology/European League Against Rheumatism 2011 remission criteria. Arthritis Rheum 2011;63:3204-15.

3. Combe B, Logeart I, Belkacemi MC, Dadoun S, Schaeverbeke T, Daurès JP, et al. Comparison of the long-term outcome for patients with rheumatoid arthritis with persistent moderate disease activity or disease remission during the first year after diagnosis: data from the ESPOIR cohort. Ann Rheum Dis 2015;74:724-9.

4. World Health Organization. Adherence to long-term therapies: evidence for action. [Internet. Accessed July 25, 2016.] Available from: www.who.int/hiv/pub/prev_care/lttherapies/en/

5. van den Bemt BJ, Zwikker HE, van Den Ende CH. Medication adherence in patients with rheumatoid arthritis: a critical appraisal of the existing literature. Expert Rev Clin Immunol 2012;8:337-51.

6. Cramer JA, Roy A, Burrell A, Fairchild CJ, Fuldeore MJ, Ollendorf DA, et al. Medication compliance and persistence: terminology and definitions. Value Health 2008;11:44-7.

7. Salt E, Frazier SK. Adherence to disease-modifying antirheumatic drugs in patients with rheumatoid arthritis: a narrative review of the literature. Orthoped Nurs 2010;29:260-75.

8. Pasma A, van't Spijker A, Hazes JM, Busschbach JJ, Luime JJ. Factors associated with adherence to pharmaceutical treatment for rheumatoid arthritis patients: a systematic review. Semin Arthritis Rheum 2013;43:18-28.

9. Contreras-Yáñez I, Ponce De León S, Cabiedes J, Rull-Gabayet M, Pascual-Ramos V. Inadequate therapy behavior is associated to disease flares in patients with rheumatoid arthritis who have achieved remission with disease-modifying antirheumatic drugs. Am J Med Sci 2010;340:282-90.

10. Viller F, Guillemin F, Briançon S, Moum T, Suurmeijer T, van den Heuvel W. Compliance to drug treatment of patients with rheumatoid arthritis: a 3 year longitudinal study. J Rheumatol 1999;26:2114-22.

11. Cannon GW, Mikuls TR, Hayden CL, Ying J, Curtis JR, Reimold $\mathrm{AM}$, et al. Merging Veterans Affairs rheumatoid arthritis registry and pharmacy data to assess methotrexate adherence and disease activity in clinical practice. Arthritis Care Res 2011;63:1680-90.

12. Waimann CA, Marengo MF, de Achaval S, Cox VL,

Garcia-Gonzalez A, Reveille JD, et al. Electronic monitoring of oral therapies in ethnically diverse and economically disadvantaged patients with rheumatoid arthritis: consequences of low adherence. Arthritis Rheum 2013;65:1421-9.

13. Hope HF, Bluett J, Barton A, Hyrich KL, Cordingley L, Verstappen SM. Psychological factors predict adherence to methotrexate in rheumatoid arthritis; findings from a systematic review of rates, predictors and associations with patient-reported and clinical outcomes. RMD Open 2016;2:e000171.

14. Smolen JS, Landewé R, Breedveld FC, Buch M, Burmester G, Dougados $\mathrm{M}$, et al. EULAR recommendations for the management of rheumatoid arthritis with synthetic and biological disease-modifying antirheumatic drugs: 2013 update. Ann Rheum Dis 2014;73:492-509.

15. Singh JA, Furst DE, Bharat A, Curtis JR, Kavanaugh AF, Kremer JM, et al. 2012 update of the 2008 American College of Rheumatology recommendations for the use of disease-modifying antirheumatic drugs and biologic agents in the treatment of rheumatoid arthritis. Arthritis Care Res 2012;64:625-39.

16. Jani M, Barton A, Warren RB, Griffiths CE, Chinoy H. The role of DMARDs in reducing the immunogenicity of TNF inhibitors in chronic inflammatory diseases. Rheumatology 2014;53:213-22.

17. de Achaval S, Suarez-Almazor ME. Treatment adherence to disease-modifying antirheumatic drugs in patients with rheumatoid arthritis and systemic lupus erythematosus. Int J Clin Rheumatol 2010;5:313-26.

18. Harrold LR, Andrade SE. Medication adherence of patients with selected rheumatic conditions: a systematic review of the literature. Semin Arthritis Rheum 2009;38:396-402.

19. de Klerk E, van Der Heijde D, Landewé R, van der Tempel H, Urquhart J, van der Linden S. Patient compliance in rheumatoid arthritis, polymyalgia rheumatica, and gout. J Rheumatol 2003;30:44-54.

20. Harley CR, Frytak JR, Tandon N. Treatment compliance and dosage administration among rheumatoid arthritis patients receiving infliximab, etanercept, or methotrexate. Am J Manag Care 2003;9:S136-43. 
21. Grijalva CG, Kaltenbach L, Arbogast PG, Mitchel EF Jr, Griffin MR. Adherence to disease-modifying antirheumatic drugs and the effects of exposure misclassification on the risk of hospital admission. Arthritis Care Res 2010;62:730-4.

22. de Thurah A, Nørgaard M, Johansen MB, Stengaard-Pedersen K. Methotrexate compliance among patients with rheumatoid arthritis: the influence of disease activity, disease duration, and co-morbidity in a 10-year longitudinal study. Scand J Rheumatol 2010; 39:197-205.

23. de Thurah A, Nørgaard M, Harder I, Stengaard-Pedersen K. Compliance with methotrexate treatment in patients with rheumatoid arthritis: influence of patients' beliefs about the medicine. A prospective cohort study. Rheumatol Int 2010; 30:1441-8.

24. Marwaha V, Bajaj N, Bajaj Bajaj S, Ghosh I, Kumar A, Vasdev V, et al. Compliance with methotrexate therapy in RA patients in rheumatology OPD of a tertiary referral centre. Ind J Rheumatol 2012;7:S30.

25. Pasma A, Schenk CV, Timman R, Busschbach JJ, van den Bemt BJ, Molenaar E, et al. Non-adherence to disease-modifying antirheumatic drugs is associated with higher disease activity in early arthritis patients in the first year of the disease. Arthritis Res Ther 2015;17:281.

26. De Cuyper E, De Gucht V, Maes S, Van Camp Y, De Clerck LS. Determinants of methotrexate adherence in rheumatoid arthritis patients. Clin Rheumatol 2016;35:1335-9.

27. Mueller S, Krueger K, Flacke J, Heinrich H, Fuchs A, Maywald U, et al. Non-adherence and non-persistence should be analyzed separately: the example of methotrexate (Mtx) therapy in the therapy of newly treated rheumatoid arthritis in Germany. Value Health 2015;18:A719.

28. Alarcón GS, Tracy IC, Blackburn WD Jr. Methotrexate in rheumatoid arthritis. Toxic effects as the major factor in limiting long-term treatment. Arthritis Rheum 1989;32:671-6.

29. Alarcón GS, Tracy IC, Strand GM, Singh K, Macaluso M. Survival and drug discontinuation analyses in a large cohort of methotrexate treated rheumatoid arthritis patients. Ann Rheum Dis 1995; 54:708-12.

30. Wolfe F, Hawley DJ, Cathey MA. Termination of slow acting antirheumatic therapy in rheumatoid arthritis: a 14-year prospective evaluation of 1017 consecutive starts. J Rheumatol 1990; 17:994-1002.

31. Scully CJ, Anderson CJ, Cannon GW. Long-term methotrexate therapy for rheumatoid arthritis. Semin Arthritis Rheum 1991;20:317-31

32. Tishler M, Caspi D, Yaron M. Long-term experience with low dose methotrexate in rheumatoid arthritis. Rheumatol Int 1993;13:103-6.

33. McKendry RJ, Dale P. Adverse effects of low dose methotrexate therapy in rheumatoid arthritis. J Rheumatol 1993;20:1850-6.

34. Salaffi F, Carotti M, Sartini A, Cervini C. A prospective study of the long-term efficacy and toxicity of low-dose methotrexate in rheumatoid arthritis. Clin Exp Rheumatol 1995;13:23-8.

35. De La Mata J, Blanco FJ, Gómez-Reino JJ. Survival analysis of disease modifying antirheumatic drugs in Spanish rheumatoid arthritis patients. Ann Rheum Dis 1995;54:881-5.

36. Keysser M, Keysser G, Keysser C. Long-term application of disease modifying antirheumatic drugs (DMARD). A single-center, observational study of 1681 patients with rheumatoid arthritis (RA). Z Rheumatol 1999;58:267-76.

37. Buchbinder R, Hall S, Sambrook PN, Champion GD, Harkness A, Lewis D, et al. Methotrexate therapy in rheumatoid arthritis: a life table review of 587 patients treated in community practice. J Rheumatol 1993;20:639-44.

38. Wluka A, Buchbinder R, Mylvaganam A, Hall S, Harkness A, Lewis $\mathrm{D}$, et al. Longterm methotrexate use in rheumatoid arthritis: 12 year followup of 460 patients treated in community practice. J Rheumatol 2000;27:1864-71.

39. Ortendahl M, Schettler JD, Fries JF. Factors influencing length of time taking methotrexate in rheumatoid arthritis. J Rheumatol 2000;27:1139-47.

40. Aletaha D, Smolen JS. Effectiveness profiles and dose dependent retention of traditional disease modifying antirheumatic drugs for rheumatoid arthritis. An observational study. J Rheumatol 2002;29:1631-8.

41. Papadopoulos NG, Alamanos Y, Papadopoulos IA, Tsifetaki N, Voulgari PV, Drosos AA. Disease modifying antirheumatic drugs in early rheumatoid arthritis: a longterm observational study. J Rheumatol 2002;29:261-6.

42. Hoekstra M, van de Laar MA, Bernelot Moens HJ, Kruijsen MW, Haagsma CJ. Longterm observational study of methotrexate use in a Dutch cohort of 1022 patients with rheumatoid arthritis. J Rheumatol 2003;30:2325-9.

43. Wolfe F, Michaud K, Stephenson B, Doyle J. Toward a definition and method of assessment of treatment failure and treatment effectiveness: the case of leflunomide versus methotrexate. J Rheumatol 2003;30:1725-32.

44. Yazici Y, Sokka T, Kautiainen H, Swearingen C, Kulman I, Pincus $\mathrm{T}$. Long term safety of methotrexate in routine clinical care: discontinuation is unusual and rarely the result of laboratory abnormalities. Ann Rheum Dis 2005;64:207-11.

45. Ideguchi $\mathrm{H}, \mathrm{Ohno} \mathrm{S}$, Ishigatsubo Y. Risk factors associated with the cumulative survival of low-dose methotrexate in 273 Japanese patients with rheumatoid arthritis. J Clin Rheumatol 2007;13:73-8.

46. Agarwal S, Zaman T, Handa R. Retention rates of disease-modifying anti-rheumatic drugs in patients with rheumatoid arthritis. Singapore Med J 2009;50:686-92.

47. Lie E, van der Heijde D, Uhlig T, Heiberg MS, Koldingsnes W, Rødevand E, et al. Effectiveness and retention rates of methotrexate in psoriatic arthritis in comparison with methotrexate-treated patients with rheumatoid arthritis. Ann Rheum Dis 2010;69:671-6.

48. Lie E, Uhlig T, van der Heijde D, Rodevand E, Kalstad S, Kaufmann C, et al. Effectiveness of sulfasalazine and methotrexate in 1102 DMARD-naive patients with early RA. Rheumatology 2012;51:670-8.

49. Kapral T, Stamm T, Machold KP, Montag K, Smolen JS, Aletaha D. Methotrexate in rheumatoid arthritis is frequently effective, even if re-employed after a previous failure. Arthritis Res Ther 2006;8:R46.

50. Bernatsky S, Ehrmann Feldman D. Discontinuation of methotrexate therapy in older patients with newly diagnosed rheumatoid arthritis: analysis of administrative health databases in Québec, Canada. Drugs Aging 2008;25:879-84.

51. Scott DG, Claydon P, Ellis C, Buchan S. A retrospective study of the effects of switching from oral to subcutaneous methotrexate: the methotrexate evaluation of Norwich treatment outcomes in rheumatoid arthritis (MENTOR) study. Rheumatology 2012;51:iii135

52. Curtis JR, Zhang J, Xie F, Beukelman T, Chen L, Fernandes J, et al. Use of oral and subcutaneous methotrexate in rheumatoid arthritis patients in the United States. Arthritis Care Res 2014;66:1604-11.

53. Gibofsky A, Cannon GW, Harrison DJ, Joseph GJ, Bitman B, Chaudhari S, et al. Discontinuation of disease-modifying anti-rheumatic drugs and clinical outcomes in the Rheumatoid Arthritis DMARD Intervention and Utilisation Study 2 (RADIUS 2). Clin Exp Rheumatol 2015;33:297-301.

54. Nikiphorou E, Negoescu A, Fitzpatrick JD, Goudie CT, Badcock A, Östör AJ, et al. Indispensable or intolerable? Methotrexate in patients with rheumatoid and psoriatic arthritis: a retrospective review of discontinuation rates from a large UK cohort. Clin Rheumatol 2014;33:609-14. 
55. Bliddal H, Eriksen SA, Christensen R, Lorenzen T, Hansen MS, Østergaard $\mathrm{M}$, et al. Adherence to methotrexate in rheumatoid arthritis: a Danish nationwide cohort study. Arthritis 2015;2015:915142.

56. Branco JC, Barcelos A, de Araújo FP, Sequeira G, Cunha I, Patto JV, et al. Utilization of subcutaneous methotrexate in rheumatoid arthritis patients after failure or intolerance to oral methotrexate: a multicenter cohort study. Adv Ther 2016;33:46-57.

57. Hazlewood GS, Thorne JC, Pope JE, Lin D, Tin D, Boire G, et al; CATCH Investigators. The comparative effectiveness of oral versus subcutaneous methotrexate for the treatment of early rheumatoid arthritis. Ann Rheum Dis 2016;75:1003-8.

58. Shea B, Swinden MV, Tanjong Ghogomu E, Ortiz Z, Katchamart W, Rader T, et al. Folic acid and folinic acid for reducing side effects in patients receiving methotrexate for rheumatoid arthritis. Cochrane Database Syst Rev 2013;5:CD000951.

59. Zwikker HE, van den Ende CH, van Lankveld WG, den Broeder AA, van den Hoogen FH, van de Mosselaar B, et al. Effectiveness of a group-based intervention to change medication beliefs and improve medication adherence in patients with rheumatoid arthritis: a randomized controlled trial. Patient Educ Couns 2014;94:356-61.

60. van den Bemt BJ, den Broeder AA, van den Hoogen FH, Benraad B, Hekster YA, van Riel PL, et al. Making the rheumatologist aware of patients' non-adherence does not improve medication adherence in patients with rheumatoid arthritis. Scand J Rheumatol 2011; 40:192-6.

61. Contreras-Yáñez I, Cabiedes J, Villa AR, Rull-Gabayet M, Pascual-Ramos V. Persistence on therapy is a major determinant of patient-, physician- and laboratory- reported outcomes in recent-onset rheumatoid arthritis patients. Clin Exp Rheumatol 2010;28:748-51.

62. Contreras-Yáñez I, Pascual-Ramos V. Window of opportunity to achieve major outcomes in early rheumatoid arthritis patients: how persistence with therapy matters. Arthritis Res Ther 2015;17:177. 